\title{
Lack of influence by endosymbiont Wolbachia on virus titer in the common bed bug, Cimex lectularius
}

\author{
Michael L. Fisher ${ }^{1,2^{*}}$, Jay F. Levine ${ }^{4}$, James S. Guy ${ }^{5}$, Hiroyuki Mochizuki ${ }^{3}$, Matthew Breen ${ }^{3}$, Coby Schal ${ }^{1}$ \\ and David W. Watson'
}

\begin{abstract}
Background: The common bed bug, Cimex lectularius, is an obligatory blood-feeding ectoparasite that requires a blood meal to molt and produce eggs. Their frequent biting to obtain blood meals and intimate association with humans increase the potential for disease transmission. However, despite more than 100 years of inquiry into bed bugs as potential disease vectors, they still have not been conclusively linked to any pathogen or disease. This ecological niche is extraordinarily rare, given that nearly every other blood-feeding arthropod is associated with some type of human or zoonotic disease. Bed bugs rely on the bacteria Wolbachia as an obligate endosymbiont to biosynthesize B vitamins, since they acquire a nutritionally deficient diet, but it is unknown if Wolbachia confers additional benefits to its bed bug host. In some insects, Wolbachia induces resistance to viruses such as Dengue, Chikungunya, West Nile, Drosophila C and Zika, and primes the insect immune system in other blood-feeding insects. Wolbachia might have evolved a similar role in its mutualistic association with the bed bug. In this study, we evaluated the influence of Wolbachia on virus replication within C. lectularius.
\end{abstract}

Methods: We used feline calicivirus as a model pathogen. We fed 40 bed bugs from an established line of Wolbachiacured and a line of Wolbachia-positive C. lectularius a virus-laden blood meal, and quantified the amount of virus over five time intervals post-feeding. The antibiotic rifampicin was used to cure bed bugs of Wolbachia.

Results: There was a significant effect of time post-feeding, as the amount of virus declined by $\sim 90 \%$ over 10 days in both groups, but no significant difference in virus titer was observed between the Wolbachia-positive and Wolbachiacured groups.

Conclusions: These findings suggest that other mechanisms are involved in virus suppression within bed bugs, independent of the influence of Wolbachia, and our conclusions underscore the need for future research.

Keywords: Cimex lectularius, Wolbachia, Endosymbiont, Cimicidae, Virus suppression, ssRNA

\section{Background}

The common bed bug, Cimex lectularius, is an obligate blood-feeding ectoparasite that has undergone a global resurgence in the last two decades (see reviews in [1]). Recent discoveries of resistance to diverse classes of insecticides [2-5] makes bed bug infestations increasingly difficult to control, but the significant fitness costs

\footnotetext{
*Correspondence: ento4life@gmail.com

${ }^{2}$ United States Navy Medical Service Corps, Raleigh, NC, USA

Full list of author information is available at the end of the article
}

associated with resistance could be exploited in integrated pest management plans [6]. Highly specialized treatments which are cost-prohibitive to most lowincome residents, coupled with insecticide resistance, exacerbate the resurgence by often failing to prevent reintroductions [7]. The profound resurgence of bed bugs in such frequent associations with humans and our domiciles could increase the threat of disease transmission.

Bed bugs, like the related triatomine bugs that transmit Trypanosoma cruzi, the etiological agent of Chagas disease, are hemimetabolous, so each instar and all adults 
require at least one blood meal to develop and reproduce. Such frequent re-feeding contaminates the indoor environment with histamine [8] and could contribute substantially to their importance as disease vectors. Yet, despite being exclusively hematophagous and intimately associated with humans, to date bed bugs have not been conclusively implicated in vector-borne disease transmission. Bed bugs can acquire a myriad of blood-borne pathogens from their hosts, but in the case of ingested viral particles, most viruses do not or are not capable of replicating once inside the bed bug (reviewed in [9-12]). Hepatitis $B$ virus (HBV) is a notable exception, however. It has been detected $>45$ days post-ingestion, after direct injection into the hemocoel, and HBV is stercorarially shed in bed bug feces, suggesting the possibility of mechanical transmission [10, 13, 14], if HBV can enter and replicate in the hemocoel. Recently, bed bugs have been shown to experimentally acquire, maintain, and effectively transmit T. cruzi [15], and Bartonella quintana, the etiological agent associated with Trench fever [16], but a survey of field-collected bed bugs failed to detect Bartonella [17]. However, the latter survey did detect Burkholderia multivorans in bed bugs.

Microbe-microbe interactions with respect to pathogen suppression have been studied in various bloodfeeding insects such as the kissing bug Rhodnius $[18,19]$, tsetse fly Glossina [20, 21], and mosquitoes (reviewed in [22]), as well as in plant-feeding fruit flies and aphids. The insect microbiome can modulate vector competence of the host for arboviruses (reviewed in $[21,23,24])$, and these influences have been most often evaluated in associations of the endosymbiont Wolbachia with fruit flies and mosquitoes. Wolbachia protects Drosophila against virus-induced mortality for Drosophila $\mathrm{C}$ virus (DCV) and Flock house virus (FHV) $[25,26]$. Wolbachia also stimulates immune gene expression in several mosquito species [27-31], and thus increases resistance to, and reduces the vector competence of Aedes aegypti, Aedes albopictus and Culex quinquefasciatus mosquitoes for viruses such as Dengue, Chikungunya, West Nile, and Zika [32-38]. Dengue, Chikungunya, Zika, West Nile, DCV, and FHV are all positive-sense single-stranded RNA viruses (+ssRNA), suggesting that the anti-viral effects induced by Wolbachia in Drosophila and mosquitoes might be limited to RNA viruses $[39,40]$.

Cimex lectularius harbors Wolbachia as its primary endosymbiotic nutritional mutualist that biosynthesizes B vitamins for its nutritionally deficient host [41, 42] in a co-dependent relationship that has presumably evolved over several million years [43]. Additional fitness benefits that the endosymbiont might confer upon bed bugs have not been investigated. Similar to the effects reported in other arthropods, Wolbachia could influence the vector competence of $C$. lectularius through mechanisms involving interactions with the host or with ingested pathogens, thus preventing certain viruses from replicating within the host. This may explain in part why bed bugs are not a major disease vector for arboviruses. The objective of this study was to compare virus titer in Wolbachia-positive and Wolbachia-free $C$. lectularius at several time intervals after ingesting a virus-laden blood meal.

\section{Methods}

\section{Establishment of Wolbachia-free C. lectularius colonies}

The Winston-Salem (WS) strain of C. lectularius was collected in Winston Salem, NC in 2008 and fed defibrinated rabbit blood (Hemostat Laboratories, Dixon, CA, USA) in an artificial feeding system, as described by Sierras \& Schal [44]. Ten adult males and 20 adult females of the WS strain were divided equally and placed into two separate $20-\mathrm{ml}$ glass vials with screened-caps and a creased section of card stock for harborage. These vials were then placed into a plastic container $(17.8 \times 12.7 \times 10.2 \mathrm{~cm})$ as additional protection against environmental bacteria. A semi-sterile incubator (Thermo Fisher Scientific, Precision Model \#3727, Waltham, MA, USA) was dedicated to rearing the Wolbachia-free $\left(\mathrm{Wb}^{-}\right)$colonies and it was maintained at $27{ }^{\circ} \mathrm{C}$ and a photoperiod of $12: 12$ (light:dark, $\mathrm{L}: \mathrm{D})$. These two colonies were fed weekly on defibrinated rabbit blood supplemented with the antibiotic rifampicin $(10 \mu \mathrm{g} / \mathrm{ml}$ blood $)$ and the Kao and Michayluk B Vitamin Solution $(10 \mu \mathrm{l} / \mathrm{ml}$ blood) (Sigma-Aldrich, St. Louis, MO, USA). Note however that this vitamin solution differs substantially from the Lake \& Friend [45] solution used by Hosokawa et al. [41]. Rearing vial (jar) size was increased periodically as colony numbers increased. To further mitigate external environmental contaminants, vials of blood were put under a portable UV light for $5 \mathrm{~min}$ immediately prior to feeding, and glass water jacketed feeders were washed with detergent and boiled for 5 min after each weekly feeding.

\section{Extraction of genomic DNA from C. lectularius}

To verify that antibiotic-treated colonies of $C$. lectularius were free of Wolbachia, a comparison to the WS- $\mathrm{Wb}^{+}$ normal strain was conducted. After several filial generations, six adults were randomly selected from each of the two antibiotic-treated and vitamin supplemented colony jars $(n=12)$ and six from the untreated WS strain. Total genomic DNA was extracted using the DNeasy Blood and Tissue kit (Qiagen, Germantown, MD, USA) with a modified purification of total DNA from animal tissues 
(spin-column) as per manufacturer's protocol. Individual bed bugs with heads removed (to minimize interference from eye pigments) were homogenized in the 1.5 $\mathrm{ml}$ microcentrifuge tube using a sterile plastic pestle and then digested overnight $(\sim 24 \mathrm{~h})$ in $180 \mu \mathrm{l}$ of ATL buffer solution, $20 \mu \mathrm{l}$ of proteinase $\mathrm{K}$, and $4 \mu \mathrm{l}$ of RNase in a 56 ${ }^{\circ} \mathrm{C}$ water bath. Following initial digestion, samples were vortexed for $15 \mathrm{~s}, 200 \mu \mathrm{l}$ of AL buffer was added, and then incubated in a $70{ }^{\circ} \mathrm{C}$ water bath for $10 \mathrm{~min}$. After incubation, $200 \mu \mathrm{l}$ of $96 \%$ ethanol was added, the mixture was then pipetted onto the DNeasy Mini spin column, and the DNA was bound, washed, and eluted into $200 \mu \mathrm{l}$ of AE buffer as outlined in the protocol. An additional wash with AW2 buffer was included to further remove salts. Samples were stored at $-20{ }^{\circ} \mathrm{C}$ until polymerase chain reaction (PCR) for Wolbachia was conducted.

\section{Verification of Wolbachia-free C. lectularius}

Conventional PCR was conducted to amplify a specific gene target within Wolbachia and measure presence or absence of Wolbachia. The Wolbachia-specific primers INTF2-FWD and INTR2-REV, adopted from Sakamoto \& Rasgon [46], targeted a region of the Wolbachia $16 \mathrm{~S}$ gene that produced a $136 \mathrm{bp}$ amplicon. The GoTaq Green Master Mix (Promega, Madison, WI, P/N M7122) and nuclease-free water were used for all reactions at the following concentrations and volumes: $12.5 \mu \mathrm{l}$ of $2 \times$ Master Mix, $2.5 \mu \mathrm{l}$ of $10 \mu \mathrm{M}$ INTF2-FWD, $2.5 \mu \mathrm{l}$ of 10 $\mu \mathrm{M}$ INTR2-REV, $5 \mu \mathrm{l}$ of template DNA, and PCR-grade nuclease-free water was added to achieve a final reaction volume of $25 \mu \mathrm{l}$. Reactions were performed using an MJ Research thermocycler (model PTC 200, Bio-Rad Laboratories, Hercules, CA, USA) with the following protocol: $95{ }^{\circ} \mathrm{C}$ for $2 \min \left(95^{\circ} \mathrm{C}\right.$ for $30 \mathrm{~s}, 60^{\circ} \mathrm{C}$ for $30 \mathrm{~s}, 72{ }^{\circ} \mathrm{C}$ for 1 min) $\times 36$ cycles, and $72{ }^{\circ} \mathrm{C}$ for $5 \mathrm{~min}$. A no-template control was used in the PCR reactions as well. A $2.0 \%$ agarose gel was used to separate the 136-bp amplicon using a $100=$ bp DNA ladder and GelRed nucleic acid stain (Biotium, Hayward, CA, USA), and visualized with a ChemiDoc-It TS2 imaging system (UVP, Upland, CA, USA).

Absolute quantification of Wolbachia in each individual bed bug was obtained with a droplet digital PCR (ddPCR) system (Model QX200, Bio-Rad Laboratories, Hercules, CA, USA) and protocol from Fisher et al. [47]. Bed bug DNA was combined with the Wolbachiaspecific primers, TaqMan probes, and the ddPCR Supermix for Probes (Bio-Rad) into PCR-ready samples. Primers for a ribosomal protein (RPL18) specific to $C$. lectularius were used as the reference gene due to its stability [48]; they produced a 137-bp amplicon. We used double-quenched TaqMan probes with a $5^{\prime}$ FAM fluorophore for Wolbachia, a $5^{\prime}$ HEX fluorophore for
C. lectularius, and $3^{\prime}$ Iowa Black ${ }^{\circledR}$ FQ quenchers with internal ZEN quenchers (Integrated DNA Technologies, Inc., Coralville, IA, USA) specific to each target. Primer and probe sequences are listed in Table 1.

The ddPCR reaction was optimized using extracted bed bug DNA from $\mathrm{Wb}^{+}$and $\mathrm{Wb}^{-}$lines. The bed bug/Wolbachia ddPCR assay comprised $22 \mu \mathrm{l}$ of $1 \times$ Droplet Supermix (Bio-Rad), $5 \mu \mathrm{l}$ of genomic DNA isolated from a bed bug, $2 \mathrm{U}$ of $M s e \mathrm{I}$ restriction enzyme (New England Biolabs, Ipswich, MA, USA), $500 \mathrm{nM}$ each of forward and reverse primers and $250 \mathrm{nM}$ each of FAM- or HEX-labeled TaqMan probes for bed bug and Wolbachia sequences, respectively. Then the 22 $\mu \mathrm{l}$ of PCR mixtures were partitioned into an emulsion of $\sim 20,000$ droplets using a QX200 ${ }^{\mathrm{TM}}$ AutoDG Droplet Digital PCR ${ }^{\mathrm{TM}}$ system (Bio-Rad). The PCR was performed on a T100 Thermal Cycler using the following protocol: $95{ }^{\circ} \mathrm{C}$ for $10 \mathrm{~min}$ and $\left(94{ }^{\circ} \mathrm{C}\right.$ for $30 \mathrm{~s}, 56^{\circ} \mathrm{C}$ for $2 \mathrm{~min}) \times 40$ cycles, and $98^{\circ} \mathrm{C}$ for $10 \mathrm{~min}$. Post PCR, droplets were analyzed on the QX200 Droplet Reader. Absolute DNA copy numbers of bed bug and Wolbachia sequences in a sample were calculated on the Poisson distribution using the Quantasoft software version 1.7.4 (Bio-Rad). Previously confirmed $\mathrm{Wb}^{+}$ bed bug DNA sample and $\mathrm{Wb}^{-}$bed bug DNA sample were included in each experiment as positive and negative controls. No-template control was also included in each experiment to ensure no non-specific amplifications. To estimate the limit of detection of the ddPCR assay, serial dilutions $(\times 5, \times 25, \times 125, \times 625, \times 3125$, $\times 15,625)$ of a DNA sample in water were prepared and repeated three times.

\section{Virus inoculations and treatments}

The experiment evaluated virus titers over time in three cohorts of bed bugs: control $\left(\mathrm{Wb}^{+}\right)$, antibiotic-vitamins $\left(\mathrm{Wb}^{-}\right)$, and $\mathrm{Wb}^{-}$maintained for 90 days on vitamin-supplemented blood without antibiotic. The latter (vitaminonly) group was removed from antibiotic 90 days prior to inoculation with virus.

Table 1 Wolbachia and Cimex lectularius reference gene primer and TaqMan probe sequences

\begin{tabular}{ll}
\hline Primer/Probe & Sequence $\left(5^{\prime}-3^{\prime}\right)$ \\
\hline INTF2 & AGTCATCATGGCCTTTATGGA \\
INTR2 & TCATGTACTCGAGTTGCAGAGT \\
Wolbachia Probe & TGGTGTCTACAATGGGCTGCAAGG \\
RPL18F & GTATGACGGAGGCAGCTAGG \\
RPL18R & AACATTCGAGCAATTCGGTA \\
Cimex Probe & ATGAGGACGGTGTCTTGCCTGTC
\end{tabular}


Feline calicivirus (FCV) was chosen as the inoculum due to its environmental stability and feasibility as a viral pathogen. Feline calicivirus is a $(+)$ ssRNA virus that is one of the primary causes of respiratory infections in felines. Virus was grown in existing Crandell Reese Feline Kidney (CrFK) cell line at the North Carolina State University College of Veterinary Medicine Clinical Virology Laboratory and stored at $-80{ }^{\circ} \mathrm{C}$ in $2 \mathrm{ml}$ aliquots per established protocols. The FCV stock was produced by first removing the growth medium from confluent $\mathrm{CrFK}$ monolayers in $75 \mathrm{~cm}^{2}$ cell culture flasks by aspiration and then $1 \mathrm{ml}$ of the virus inoculum was added to each flask. Flasks were incubated at $37{ }^{\circ} \mathrm{C}$ in $5 \% \mathrm{CO}_{2}$ atmosphere for $90 \mathrm{~min}$ to allow for virus adsorption. Each flask then received $10 \mathrm{ml}$ of maintenance medium (MEM-2\% fetal bovine serum), and incubated $16 \mathrm{~h}$ at $37{ }^{\circ} \mathrm{C}$ in $5 \% \mathrm{CO}_{2}$, which resulted in virus-induced destruction of $\sim 90 \%$ of the monolayer.

In each feeding, 40 individual bed bugs were chosen randomly, placed in $7 \mathrm{ml}$ glass vials with screened-caps, and fed as previously described for $15 \mathrm{~min}$ on fresh defibrinated rabbit blood supplemented with $1 \mathrm{ml} \mathrm{FCV}\left(10^{7}\right.$ $\mathrm{CCID}_{50} / \mathrm{ml}$ ) per $1 \mathrm{ml}$ of blood. The $\mathrm{CCID}_{50}$ is the $50 \%$ cell culture infective dose, as defined below. Bed bugs were starved 7 days prior to feeding FCV-laden blood. Individuals that did not feed or only partially fed were removed
Three randomly chosen bed bugs were removed from each cohort, sexed, and surface sterilized with $0.05 \%$ $\mathrm{NaClO}$ and $70 \%$ ethanol. Surface-sterilized bugs were homogenized in $3.5 \mathrm{ml}$ round-bottom polystyrene tubes (Sarstedt, Nümbrecht, Germany) in $0.5 \mathrm{ml}$ of Dulbecco's Modified Eagle's Medium (DMEM) (Caisson Laboratories, Smithfield, UT, USA) with sterile plastic pestles and the tubes were centrifuged $(8000 \times \mathrm{rpm}$ for $1 \mathrm{~min})$. A volume of $220 \mu \mathrm{l}$ of the supernatant was pipetted into a new $3.5 \mathrm{ml}$ tube with $2.2 \mathrm{ml}$ of DMEM, and serial 10 -fold dilutions $\left(10^{-1}\right.$ to $\left.10^{-6}\right)$ were performed to obtain virus titration. A total of $100 \mu \mathrm{l}$ of each dilution was placed in 4 wells (technical replicates; portrait orientation) of a flat-bottomed, 96-well plate, and $100 \mu \mathrm{l}$ of CrFK cells was added to each well. Each plate contained a row of wells as a cell control with no virus. Plates were incubated at $37^{\circ} \mathrm{C}$ for $5 \mathrm{~d}$ [49-51] and then stained with crystal violet (50 $\mu \mathrm{l} /$ well). FCV is a highly lytic virus; after 5 days, only wells with uninfected cells show crystal violet staining.

In each virus dilution, the percentage of dead (infected) cells was visually determined for each well. To measure the infectious virus titer, the $50 \%$ cell culture infective dose $\left(\mathrm{CCID}_{50}\right)$ endpoint dilution assay was used to quantify the amount of virus required to kill $50 \%$ of infected CrFK cells as described by Reed \& Muench [52], if the $50 \%$ dose fell between two dilutions. The Reed-Muench index formula reads as follows:

(\% infected at dilution immediately above $50 \%)-50 \%$

$\overline{(\% \text { infected at dilution immediately above } 50 \%)-(\% \text { infected at dilution immediately below } 50 \%)}$

and discarded. Vials were kept thereafter at room temperature under a sterile laminar flow hood and 12:12 (L:D) photoperiod.

\section{Quantification of FCV in C. lectularius}

Bed bugs were killed at the following time intervals: 5 hours (h), $24 \mathrm{~h}, 4$ days (d), $7 \mathrm{~d}$, and $10 \mathrm{~d}$ post-feeding.

\section{Sex ratio of male and female $C$. lectularius chosen}

The sex ratio of the three bed bugs randomly chosen per time interval post-feeding of FCV is shown in Table 2. Both $\mathrm{Wb}^{-}$and $\mathrm{Wb}^{-} 90 \mathrm{~d}$ groups had close to $1: 1$ male:female, but slightly more males were chosen in the $\mathrm{Wb}^{+}$group at 1:0.67 male:female ratio.

Table 2 Number of males and females in each bed bug group at five sampling time intervals post-feeding

\begin{tabular}{|c|c|c|c|c|c|c|}
\hline \multirow[t]{2}{*}{ Time post-feeding } & \multicolumn{2}{|c|}{$\mathrm{Wb}^{+}$} & \multicolumn{2}{|c|}{$\mathrm{Wb}^{-}$} & \multicolumn{2}{|c|}{$W b^{-} 90 d$} \\
\hline & M & $\mathrm{F}$ & M & $\mathrm{F}$ & $M$ & $\mathrm{~F}$ \\
\hline 5 hours & 1 & 2 & 1 & 2 & 0 & 3 \\
\hline 24 hours & 1 & 2 & 2 & 1 & 1 & 2 \\
\hline 4 days & 2 & 1 & 2 & 1 & 2 & 1 \\
\hline 7 days & 2 & 1 & 1 & 2 & 2 & 1 \\
\hline 10 days & 3 & 0 & 2 & 1 & 2 & 1 \\
\hline Total & 9 & 6 & 8 & 7 & 7 & 8 \\
\hline
\end{tabular}

Abbreviations: $\mathrm{Wb}^{+}$, colony containing Wolbachia; $\mathrm{Wb}^{-}$, two colonies cured of Wolbachia with the antibiotic rifampicin; Wb- $90 \mathrm{~d}$, colony cured of Wolbachia with antibiotic, then reared for 90 days on blood supplemented with vitamins but no antibiotic; F, female; $M$, male 


\section{Statistical analysis}

Differences in the mean virus titer in $\mathrm{CCID}_{50} / \mathrm{ml}$ were analyzed with a two-sample t-test that assumed unequal variances using a 95\% confidence interval with SPSS Version 19 (IBM Corp., Armonk, NY). A P-value $<0.05$ was considered significantly different. A General Linear Model Repeated Measures analysis (Wilks' Lambda $\{\lambda\}$ ) was also conducted in SPSS to identify any effect of time, treatment group, replicate, and interactions between these variables on virus titer.

\section{Results}

\section{Confirmation of Wolbachia-free Cimex lectularius colonies}

The conventional PCR results confirmed that the bed bug colony treated with rifampicin and supplemented with B vitamins contained no Wolbachia. As well, the colony removed from antibiotics and maintained on vitaminsupplemented blood contained no Wolbachia (Fig. 1). The ddPCR also confirmed the absence of Wolbachia [47] Absolute quantification detected 0 copy numbers of the $16 \mathrm{~S}$ Wolbachia target in both bed bug colonies treated with antibiotics and those later removed from antibiotics for $90 \mathrm{~d}$ [47]. The ddPCR was highly sensitive

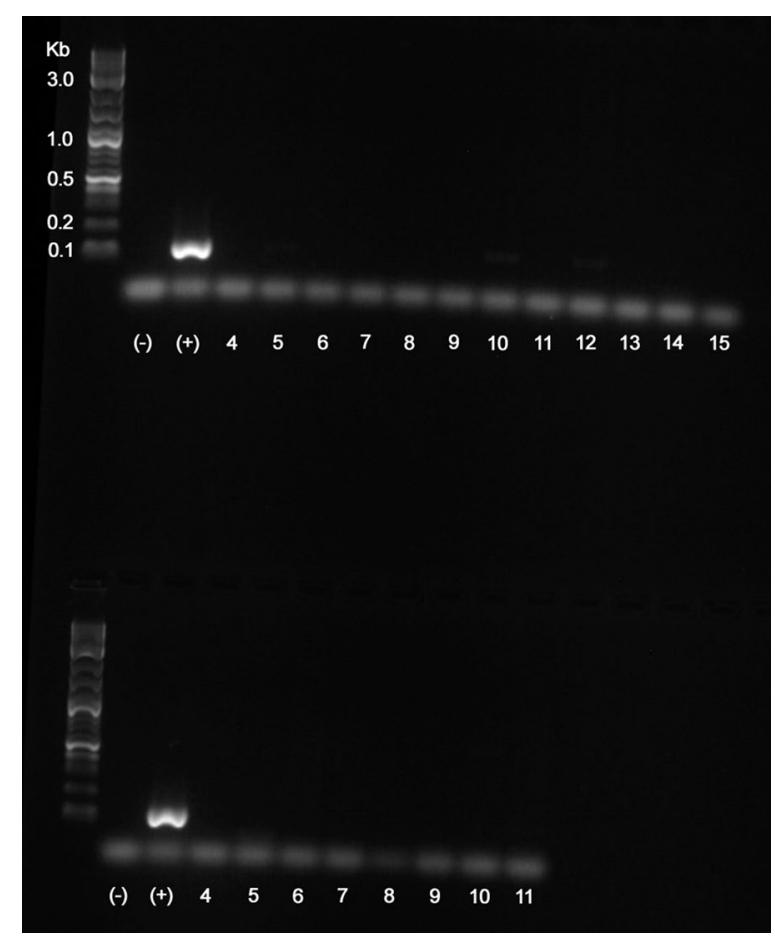

Fig. 1 PCR results illustrating absence of Wolbachia in bed bugs. Top row: Lanes 4-9: bed bugs treated with the antibiotic and ingested blood supplemented with B vitamins; Lanes 10-15: bed bugs removed from antibiotics and maintained on blood supplemented with B vitamins for 30 days. Bottom row: Lanes 4-11: bed bugs removed from antibiotics and maintained on blood supplemented with $B$ vitamins only for 60 days
Table 3 FCV titers $\left(\log _{10} C C D_{50} / 0.1 \mathrm{ml}\right)$ in each of the three bed bug groups at five sampling time intervals post-feeding

\begin{tabular}{llllll}
\hline Treatment & \multicolumn{5}{l}{ Mean $( \pm \mathrm{SE}) \mathrm{FCV}$ titers $\left(\log _{10} C \mathrm{CID} \mathrm{D}_{50} / 0.1 \mathrm{ml}\right)$} \\
\cline { 2 - 6 } & 5 hours & 24 hours & 4 days & 7 days & 10 days \\
\hline $\mathrm{Wb}^{+}$ & $4.67 \pm 0.00$ & $4.56 \pm 0.06$ & $4.44 \pm 0.06$ & $3.06 \pm 0.71$ & $3.22 \pm 0.49$ \\
$\mathrm{~Wb}^{-}$ & $4.89 \pm 0.31$ & $4.56 \pm 0.11$ & $5.11 \pm 0.11$ & $3.50 \pm 0.50$ & $3.78 \pm 0.22$ \\
$\mathrm{~Wb}^{-} 90 \mathrm{~d}$ & $4.50 \pm 0.40$ & $4.45 \pm 0.00$ & $4.17 \pm 0.17$ & $3.67 \pm 0.17$ & $3.72 \pm 0.15$
\end{tabular}

Abbreviations: $\mathrm{Wb}^{+}$, colony containing Wolbachia; $\mathrm{Wb}^{-}$, two colonies cured of Wolbachia with the antibiotic rifampicin; $\mathrm{Wb}^{-} 90 \mathrm{~d}$, colony cured of Wolbachia with antibiotic, then reared for 90 days on blood supplemented with vitamins but no antibiotic

for detection of Wolbachia and bed bug DNA. Theoretical values (1.76 copies of Wolbachia $\mathrm{DNA} / \mu \mathrm{l} ; 1.00$ copies of RPL18 DNA/ $\mu \mathrm{l})$ and measured values (1.40 copies of Wolbachia DNA/ $\mu \mathrm{l} ; 1.00$ copies of RPL18 DNA/ $\mu \mathrm{l}$ ) matched well with high reproducibility even at extremely low concentrations (15,625-fold dilution). No Wolbachia or bed bug DNA was detected in the no-template controls.

\section{FCV acquisition and titer comparison in bed bug groups}

We estimated that adult bed bugs ingested between 4-6 $\mu \mathrm{l}$ of blood meal $(3.92 \mu \mathrm{l}$ for adult males in Sierras \& Schal [44]), which corresponds to $10^{4}$ virus in a single feeding. Live virus was detected in relatively large amounts in all treatment groups at all time intervals up to $10 \mathrm{~d}$ (Table 3). No significant differences were observed in FCV titer among the three treatment groups at any of the five sampling intervals, with the exception of in the $\mathrm{Wb}^{-}$group compared to the $\mathrm{Wb}^{-} 90 \mathrm{~d}$ at the $4 \mathrm{~d}$ interval $\left(t_{(2)}=-4.724, P=0.0179\right)$.

There was a significant decline in FCV titer over time after the blood meal (Wilks' $\lambda=0.014, F_{(2,4)}=36.48$, $\left.P=0.0271 ; \eta^{2}=0.986\right)$, with an average of $90.7 \%$ decline across all three treatments after $10 \mathrm{~d}$, ranging from $96.5 \%$ decline in the $\mathrm{Wb}^{+}$group, $92.2 \%$ in the $\mathrm{Wb}^{-}$group, and $83.4 \%$ decline in the $\mathrm{Wb}^{-} 90 \mathrm{~d}$ group (Table 3$)$. However, there was no effect of treatment $\left(F_{(2,4)}=0.359, P=0.575\right)$ or replicate on FCV titer $\left(F_{(2,8)}=0.127, P=0.884\right)$, and there was no effect of time*treatment (Wilks' $\lambda=0.072$, $\left.F_{(2,4)}=6.48, \quad P=0.1381, \eta^{2}=0.928\right)$, or time* replicate (Wilks' $\lambda=0.05, F_{(4,8)}=1.73, P=0.3143, \eta^{2}=0.775$ ). No infection was observed in any of the cell line controls in any of the three bed bug groups at any sampling time interval. We observed no mortality in any of the FCVinfected bed bugs that were left in the vials after feeding on FCV-supplemented blood. 


\section{Discussion}

In 1887 Elias Metschnikoff was the first to suspect that bed bugs could serve as a vector of human pathogens, but definitive proof having been elusive, several generations of researchers remained unconvinced [53]. Even today, bed bugs are not considered important vectors of any specific pathogen, although they are broadly considered medically-important due to the clinical manifestations of bite site reactions and the psychological effects that infestations can elicit $[12,54,55]$. Although more than 45 pathogens (bacteria, viruses, fungi, protozoans) have been detected in bed bugs [10], <10\% are known to replicate within the bed bug. Their apparent refractory state to human pathogens is remarkable, as nearly every other blood-feeding arthropod (mosquitoes, biting flies, lice, fleas, ticks) is associated with some type of disease or pathogen, and it may reflect the intimate and long evolutionary association of bed bugs with humans. An alternative potential human health concern is the histamine contamination that is possibly a contributing factor in allergic responses [8].

We used feline calicivirus (FCV) as a model pathogen in our investigation because it is environmentally stable, it represents RNA viruses, and it could be transmitted by bed bugs in residential settings. Since FCV is not a human pathogen, it served as a useful surrogate for other more infectious ssRNA virus without placing laboratory workers at risk of infection. Our results showed that FCV did not replicate within $C$. lectularius, but relatively high FCV titers were maintained in bed bugs $10 \mathrm{~d}$ after they were inoculated through a blood meal. The amount of FCV decreased dramatically over time in all of our treatment groups, from a $29 \%$ decline from 5 to 24 hours after the blood meal, to a $91 \%$ decline after 10 days. We found no evidence from these patterns that FCV could replicate within the bed bug. Although we observed a large decline in FCV, the overall decline was much smaller than other viruses evaluated in bed bugs, such as HIV and Yellow fever, where little to no replication was reported to occur $[56,57]$. Importantly however, the decline in FCV titer was independent of the presence or absence of endosymbiotic Wolbachia (Table 3).

It is important to note that secondary effects from the rifampicin treatment could have affected the interaction of the bed bug with FCV. The Wolbachia-cured $\left(\mathrm{Wb}^{-}\right)$group was treated with antibiotic during weekly blood meals before the experiment started. Therefore, this group was also expected to suffer from an altered gut microbiome, whose possible interactions with and effects on FCV are not known. Another Wolbachiacured group ( $\mathrm{Wb}^{-} 90 \mathrm{~d}$ ) was weaned off rifampicin 3 months before the experiment started. We expected this group to be less affected by the antibiotic, and its gut microbial community might have recovered during the three months, which represented less than two generations. This group, however, was not different from the other two groups, including the Wolbachiacontaining group $\left(\mathrm{Wb}^{+}\right)$which was never exposed to rifampicin, suggesting that neither Wolbachia nor the gut microbiome influenced the FCV titers.

The absence of a Wolbachia influence on FCV titers might be related to minimal interactions between the symbiont and the virus. Factors related to the physiological conditions of the midgut, inability of FCV to permeate midgut barriers, and host immune responses may minimize these interactions. Wolbachia's intracellular sequestration within the bed bug bacteriome might further diminish contact between these two microbes.

As blood is ingested, FCV would interact with a wide range of bed bug salivary proteins that are secreted to counteract the vertebrate host's hemostasis (platelet aggregation, fibrin crosslinking, vasoconstriction, local immune responses). The bed bug genome revealed expanded families of salivary apyrases, nitric oxide carriers, and members of the Ap4a_hydrolase family [58]. Bed bug saliva contains substances that decrease ingested pathogen virulence and titers [11], but it is not known if viruses might be affected by these salivary components.

After the bed bug ingests a blood meal containing FCV, the virus must interact with the insect alimentary canal, penetrate the hemocoel, and for effective transmission with subsequent blood meals the virus needs to replicate in the salivary glands or other tissues associated with the mouthparts. Alternatively, if the virus survives passage through the alimentary canal, it can be transmitted in feces, though this pathway is considered less efficient. Mildly acidic to neutral midgut $\mathrm{pH}(5-7)$ is ideal for a wide range of microorganisms, but in most insects the midgut is alkaline $(\mathrm{pH} \geq 8)$ and typically unfavorable for most microorganisms [59, 60]. Adult mosquito midgut $\mathrm{pH}$ is between 7.2-7.9 immediately prior to blood-meal ingestion, and returns to $\mathrm{pH} 7.3$ after digestion [61]. The gut $\mathrm{pH}$ of the bed bug is not known, but if it is similar to the mosquito, it likely is reasonably favorable to FCV. Feline calici virus is a non-enveloping, environmentally stable virus, able to survive acidic to neutral $\mathrm{pH}$ [62]. Therefore, FCV likely survives the midgut, although the activity of digestive enzymes may hinder FCV. The bed bug genome revealed 187 potential digestive enzymes, including serine proteases, a large expansion of cathepsin D genes, and aspartic proteases that are specifically adapted for acidic $\mathrm{pH}$ [58].

We did not determine whether FCV was able to cross the midgut barrier and enter the bed bug hemocoel. Many insects, including blood feeders, form a peritrophic 
membrane (PM) around the food bolus during or shortly after ingestion. The PM is a physical barrier that protects the midgut lumen. A pathogen or parasite must penetrate the PM and invade the midgut tissues before it can cross into the hemolymph. Although the PM is absent in most Hemiptera [61], C. lectularius, R. prolixus, and Triatoma infestans all have a modified PM effectively known as a 'plexiform surface coat' type PM that is permeable to digestive enzymes [63]. The PM is one of many midgut effector mechanisms such as lectins, reactive oxygen species, nitric oxide, melanization through the prophenoloxidase cascade, and pattern recognition receptors that comprise the humoral immunity protecting the insect host against infections [64]. Several pathogens of insects escape humoral response and evade the impermeability of the PM by invading the tissues before the PM is fully developed [61]. The mosquito PM is impermeable to particles $>148 \mathrm{kDa}[65]$, and most viruses are $\sim 2000 \mathrm{kDa}$ [66]. To permeate through the PM, viruses and other enteric pathogens must secrete proteolytic enzymes that degrade membrane proteins [66]. Once crossed into the hemolymph, most arboviruses infect all compartments of an arthropod vector [64].

If FCV crossed the PM into the hemolymph, the next host defense would be a systemic immune response by $C$. lectularius by way of hemocytes, activation of proteases, production of antimicrobial peptides, or immune signal transduction pathway activation (Toll, imd, JAK-STAT) by the fat body that could lower FCV titer. The genome of $C$. lectularius has revealed members of all these pathways, as well as the RNA interference pathway [58] and transcriptomic analysis that supports the expression of the entire suite of putative immune defense pathways [67]. It is generally thought that the combination of blood-feeding and traumatic insemination have selected for a highly adapted immune response in the bed bug. For example, the female paragenital system has an overabundance of hemocytes [55], and bed bug hemolymph and ejaculate are suspected to contain substances or "neutralizing factors" that decrease ingested pathogen virulence and titers [11]. We did not determine whether FCV was present in the bed bug hemolymph. We might speculate, however, that significant declines in the FCV titer over 10 days would suggest that FCV was attacked either in the digestive tract or in the hemolymph of the bed bug, but apparently independently of the presence of Wolbachia.

Wolbachia has been shown to play important roles in mediating host-microbe interactions. In Drosophila, higher Wolbachia densities correlate with greater antiviral protection $[68,69]$, and as a model for studying Blue tongue virus (BTV) replication within blood-feeding Culicoides midges, BTV replicated significantly in all cell lines examined from BTV-infected Drosophila melanogaster reared without Wolbachia [70]. Wolbachia also mediates immunocompetence in isopods [71]. In some mosquito-Wolbachia-virus interactions, Wolbachia primes the mosquito innate immune system $[28,31,36]$, but there is evidence that in several mosquito species where Wolbachia naturally occurs, the presence of Wolbachia has little to no influence on resistance to or suppression of viruses [72,73].

The localization of Wolbachia within the host is relevant to its involvement in pathogen suppression. In many insects, Wolbachia is systemically distributed either throughout the body or in specialized but highly diffuse tissues (e.g. fat body, integument). In C. lectularius on the other hand, Wolbachia resides exclusively in a bacteriome of both sexes, in association with the gonads [41] and would likely not encounter the virus to initiate a symbiont-mediated immune response. While Wolbachia could respond to immune challenges by remotely signaling to the fat body and hemocytes, its location in the gonad-associated bacteriome would make such a signaling pathway less likely than in mosquitoes, flies and isopods.

Bed bugs do not appear to be competent vectors for ssRNA human viruses associated with disease in humans, and their status as a medically important vector of disease remains uncertain. However, bed bugs could be more important vectors of dsDNA viruses such as hepatitis B virus (HBV). Moreover, C. lectularius and other cimicids conceivably may have a greater significance from a veterinary medicine perspective. Other species of cimicids may be epidemiologically important in diseases of birds and bats yet to be investigated [74]. The swallow bug Oeciacus vicarius can vector several arboviruses [75], and can experimentally transmit Fort Morgan virus to uninfected birds [76]. Commercial poultry operations are likely to have heavy infestations of ectoparasites [77], and the role of bed bugs as primary or bridge vectors of avian diseases is essentially unknown. Interestingly, despite an interest over the past 100 years in the potential of bed bugs to serve as vectors of human pathogens, including HIV, HBV, Ebola, Yellow Fever, Polio, Rabies, Plasmodium, Leishmania, Yersinia, and numerous bacterial species, immune responses by bed bugs when challenged with a pathogen remain poorly understood.

\section{Conclusions}

To our knowledge, this is the first study to evaluate the influence of Wolbachia on virus titer in Cimex lectularius. Our results indicate that Wolbachia does not play a role in ssRNA virus suppression in bed bugs, in contrast to its involvement in several other hematophagous insects. These results offer further supporting evidence that bed bugs are likely not competent vectors of ssRNA 
viruses, adding feline calicivirus to the list of viruses examined thus far. Our conclusions underscore the need for future research to include (i) quantification of virus titers in various body compartments, particularly the hemolymph and salivary glands; (ii) hemocoel injections of virus for titer comparison in Wolbachia-free and normal bed bugs; and (iii) investigation of the ability of the bed bug to transmit the virus upon re-feeding.

\section{Abbreviations}

Wb: Wolbachia; PCR: polymerase chain reaction; ddPCR: droplet digital polymerase chain reaction; FCV: feline calicivirus; PM: peritrophic membrane.

\section{Acknowledgements}

We generously thank the clinical virology technicians Melissa West and Leah Scarborough for their assistance and expertise with FCV dilutions and infection of CrFK cell line. We also thank Rick Santangelo for carefully maintaining bed bugs colonies and sorting bugs for these experiments.

\section{Disclaimer}

The views expressed in this article are those of the authors and do not necessarily reflect the official policy or position of the Department of the Navy, Department of Defense, or the United States Government. "MLF is a military service member (or employee of the U.S. Government). This work was prepared as part of MLF official duties. Title 17, USC, \$105 provides that 'Copyright protection under this title is not available for any work of the U.S. Government.' Title 17, USC, §101 defines a U.S. Government work as a work prepared by a military service member or employee of the U.S. Government as part of that person's official duties."

\section{Authors' contributions}

All authors made significant contributions to the study. MLF contributed to drafting the manuscript, critical revisions of the manuscript, acquisition of data, and interpretation of data. JFL and JSG contributed to the concept and design of virus inoculation, and were involved in the critical revisions of the manuscript. HM made substantial contributions to the acquisition and interpretation of ddPCR data, and was involved in the critical revisions of the manuscript. MB was involved in the critical revisions of the manuscript. CS was involved in the critical revisions of the manuscript and interpretation of data. DWW was involved in the critical revisions of the manuscript and interpretation of data. All authors read and approved the final manuscript.

\section{Funding}

This work was funded in part by grants from the US Department of Housing and Urban Development Healthy Homes Program (NCHHU0017-13) and the Alfred P. Sloan Foundation (2013-5-35 MBE), the Blanton J. Whitmire Endowment, WM Keck Center for Behavioral Biology, and the Department of Entomology and Plant Pathology, all at North Carolina State University. This study was funded by W. M. Keck Foundation (2016scholarship).

\section{Availability of data and materials}

Data supporting the conclusions of this article are provided within the article. Raw datasets are available upon request.

\section{Ethics approval and consent to participate}

Not applicable.

\section{Consent for publication}

Not applicable.

\section{Competing interests}

The authors declare that they have no competing interests.

\section{Author details}

${ }^{1}$ Department of Entomology and Plant Pathology, North Carolina State University, Raleigh, NC, USA. ${ }^{2}$ United States Navy Medical Service Corps, Raleigh, NC, USA. ${ }^{3}$ Department of Molecular Biomedical Sciences, North Carolina State
University, Raleigh, NC, USA. ${ }^{4}$ Department of Marine, Earth and Atmospheric Sciences, North Carolina State University, Raleigh, NC, USA. ${ }^{5}$ Department of Population Health and Pathobiology, North Carolina State University, Raleigh, NC 27607, USA.

Received: 29 May 2019 Accepted: 31 August 2019

Published online: 09 September 2019

\section{References}

1. Doggett SL, Miller DM, Lee C-Y, editors. Advances in the biology and management of modern bed bugs. Hoboken, New Jersey: Wiley; 2018.

2. Romero A, Anderson TD. High levels of resistance in the common bed bug, Cimex lectularius (Hemiptera: Cimicidae), to neonicotinoid insecticides. J Med Entomol. 2016;53:727-31.

3. Lilly DG, Latham SL, Webb CE, Doggett SL. Cuticle thickening in a pyrethroid-resistant strain of the common bed bug, Cimex lectularius L. (Hemiptera: Cimicidae). PLoS ONE. 2016;1 1:e0153302.

4. Lilly DG, Webb CE, Doggett SL. Evidence of tolerance to silica-based desiccant dusts in a pyrethroid-resistant strain of Cimex lectularius (Hemiptera: Cimicidae). Insects. 2016;7:74.

5. Koganemaru R, Miller DM, Adelman ZN. Robust cuticular penetration resistance in the common bed bug (Cimex lectularius L.) correlates with increased steady-state transcript levels of CPR-type cuticle protein genes. Pestic Biochem Physiol. 2013;106:190-7.

6. Gordon JR, Potter MF, Haynes KF. Insecticide resistance in the bed bug comes with a cost. Sci Rep. 2015:5:10807.

7. Raab RW, Moore JE, Vargo EL, Rose L, Raab J, Culbreth M, et al. New introductions, spread of existing matrilines, and high rates of pyrethroid resistance result in chronic infestations of bed bugs (Cimex lectularius L.) in lower-income housing. PLOS ONE. 2016;11:e0117805.

8. DeVries ZC, Santangelo RG, Barbarin AM, Schal C. Histamine as an emergent indoor contaminant: accumulation and persistence in bed bug infested homes. PLoS ONE. 2018:13:e0192462.

9. Doggett SL. Bed bugs and infectious diseases. In: Doggett SL, Miller DM, Lee C-Y, editors. Advances in the biology and management of modern bed bugs. Hoboken, New Jersey: Wiley; 2018. p. 117-26.

10. Delaunay P, Blanc V, Del Giudice P, Levy-Bencheton A, Chosidow O, Marty P, et al. Bedbugs and infectious diseases. Clin Infect Dis. 2011;52:200-10.

11. Lai O, Ho D, Glick S, Jagdeo J. Bed bugs and possible transmission of human pathogens: a systematic review. Arch Dermatol Res. 2016;308:531-8.

12. Goddard J, deShazo R. Bed bugs (Cimex lectularius) and clinical consequences of their bites. J Am Med Assoc. 2009;301:1358-66.

13. Blow JA, Turell MJ, Silverman AL, Walker ED. Stercorarial shedding and transtadial transmission of hepatitis B virus by common bed bugs (Hemiptera: Cimicidae). J Med Entomol. 2001;38:694-700.

14. Silverman AL, Qu LH, Blow J, Zitron IM, Gordon SC, Walker ED. Assessment of hepatitis B virus DNA and hepatitis C virus RNA in the common bedbug (Cimex lectularius L.) and kissing bug (Rodnius prolixus). Am J Gastroenterol. 2001;96:2194-8.

15. Salazar R, Castillo-Neyra R, Tustin AW, Borrini-Mayorí K, Náquira C, Levy MZ. Bed bugs (Cimex lectularius) as vectors of Trypanosoma cruzi. Am J Trop Med Hyg. 2015;92:331-5.

16. Leulmi H, Bitam I, Berenger JM, Lepidi H, Rolain JM, Almeras L, et al. Competence of Cimex lectularius bed bugs for the transmission of Bartonella quintana, the agent of trench fever. PLoS NegI Trop Dis. 2015;9:e0003871.

17. Saenz VL, Maggi RG, Breitschwerdt EB, Kim J, Vargo EL, Schal C. Survey of Bartonella spp. in U.S. bed bugs detects Burkholderia multivorans but not Bartonella. PLoS ONE. 2013;8:e0073661.

18. Azambuja P, Garcia ES, Ratcliffe NA. Gut microbiota and parasite transmission by insect vectors. Trends Parasitol. 2005;21:568-72.

19. Beard CB, Cordon-Rosales C, Durvasula RV. Bacterial symbionts of the Triatominae and their potential use in control of Chagas disease transmission. Annu Rev Entomol. 2002;47:123-41.

20. Weiss BL, Wang JW, Maltz MA, Wu YN, Aksoy S. Trypanosome infection establishment in the tsetse fly gut is influenced by microbiome-regulated host immune barriers. PLoS Pathog. 2013;9:12.

21. Weiss B, Aksoy S. Microbiome influences on insect host vector competence. Trends Parasitol. 2011;27:514-22. 
22. van Tol S, Dimopoulos G. Influences of the mosquito microbiota on vector competence. In: Raikhel AS, editor. Progress in mosquito research, vol. 51. London: Academic Press Ltd-Elsevier Science Ltd; 2016. p. 243-91.

23. Johnson KN. Bacteria and antiviral immunity in insects. Curr Opin Insect Sci. 2015;8:97-103.

24. Jupatanakul N, Sim S, Dimopoulos G. The insect microbiome modulates vector competence for arboviruses. Viruses-Basel. 2014;6:4294-313.

25. Teixeira L, Ferreira A, Ashburner M. The bacterial symbiont Wolbachia induces resistance to RNA viral infections in Drosophila melanogaster. PLoS Biol. 2008;6:2753-63.

26. Wong ZS, Hedges LM, Brownlie JC, Johnson KN. Wolbachia-mediated antibacterial protection and immune gene regulation in Drosophila. PLoS ONE. 2011:6:9.

27. Hughes GL, Koga R, Xue P, Fukatsu T, Rasgon JL. Wolbachia infections are virulent and inhibit the human malaria parasite Plasmodium falciparum in Anopheles gambiae. PLoS Pathog. 2011;7:8.

28. Kambris Z, Blagborough AM, Pinto SB, Blagrove MSC, Godfray HCJ, Sinden RE, et al. Wolbachia stimulates immune gene expression and inhibits Plasmodium development in Anopheles gambiae. PLoS Pathog. 2010;6:9.

29. Kambris Z, Cook PE, Phuc HK, Sinkins SP. Immune activation by lifeshortening Wolbachia and reduced filarial competence in mosquitoes. Science. 2009:326:134-6.

30. McFarlane M, Arias-Goeta C, Martin E, O'Hara Z, Lulla A, Mousson L, et al. Characterization of Aedes aegypti innate-immune pathways that limit Chikungunya virus replication. PLoS Negl Trop Dis. 2014;8:11.

31. Pan XL, Zhou GL, Wu JH, Bian GW, Lu P, Raikhel AS, et al. Wolbachia induces reactive oxygen species (ROS)-dependent activation of the Toll pathway to control dengue virus in the mosquito Aedes aegypti. Proc Natl Acad Sci USA. 2012;109:E23-31.

32. Tan CH, Wong PJ, Li MI, Yang HT, Ng LC, O'Neill SL. WMel limits Zika and chikungunya virus infection in a Singapore Wolbachia-introgressed Ae. aegypti strain, wMel-Sg. PLoS Negl Trop Dis. 2017;11:10.

33. Aliota MT, Peinado SA, Velez ID, Osorio JE. The wMel strain of Wolbachia reduces transmission of Zika virus by Aedes aegypti. Sci Rep. 2016;6:7.

34. Carrington LB, Tran BCN, Le NTH, Luong TTH, Nguyen TT, Nguyen PT, et al. Field-and clinically derived estimates of Wolbachia-mediated blocking of dengue virus transmission potential in Aedes aegypti mosquitoes. Proc Natl Acad Sci USA. 2018;115:361-6.

35. Glaser RL, Meola MA. The native Wolbachia endosymbionts of Drosophila melanogaster and Culex quinquefasciatus increase host resistance to West Nile virus infection. PLOS ONE. 2010;5:11

36. Moreira LA, Iturbe-Ormaetxe I, Jeffery JA, Lu GJ, Pyke AT, Hedges LM, et al. A Wolbachia symbiont in Aedes aegypti limits infection with dengue, chikungunya, and Plasmodium. Cell. 2009;139:1268-78.

37. Mousson L, Zouache K, Arias-Goeta C, Raquin V, Mavingui P, Failloux AB. The native Wolbachia symbionts limit transmission of dengue virus in Aedes albopictus. PLoS Negl Trop Dis. 2012;6:10.

38. Zhang GM, Hussain M, O'Neill SL, Asgari S. Wolbachia uses a host microRNA to regulate transcripts of a methyltransferase, contributing to dengue virus inhibition in Aedes aegypti. Proc Natl Acad Sci USA. 2013;110:10276-81

39. Brownlie JC, Johnson KN. Symbiont-mediated protection in insect hosts Trends Microbiol. 2009;17:348-54.

40. Sicard M, Dittmer J, Greve P, Bouchon D, Braquart-Varnier C. A host as an ecosystem: Wolbachia coping with environmental constraints. Environ Microbiol. 2014;16:3583-607.

41. Hosokawa T, Koga R, Kikuchi Y, Meng XY, Fukatsu T. Wolbachia as a bacteriocyte-associated nutritional mutualist. Proc Natl Acad Sci USA. 2010;107:769-74.

42. Moriyama M, Nikoh N, Hosokawa T, Fukatsu T. Riboflavin provisioning underlies Wolbachia's fitness contribution to its insect host. Mbio. 2015;6:e01732.

43. Nikoh N, Hosokawa T, Moriyama M, Oshima K, Hattori M, Fukatsu T. Evolutionary origin of insect-Wolbachia nutritional mutualism. Proc Natl Acad Sci USA. 2014;111:10257-62.

44. Sierras A, Schal C. Comparison of ingestion and topical application of insecticides against the common bed bug, Cimex lectularius (Hemiptera: Cimicidae). Pest Manag Sci. 2017;73:521-7.

45. Lake P, Friend WG. Use of artificial diets to determine some of effects of Nocardia rhodnii on development of Rhodnius prolixus. J Insect Physiol. 1968;14:543-62.
46. Sakamoto JM, Rasgon JL. Geographic distribution of Wolbachia infections in Cimex lectularius (Heteroptera: Cimicidae). J Med Entomol. 2006:43:696-700.

47. Fisher ML, Watson DW, Osborne JA, Mochizuki H, Breen M, Schal C. Growth kinetics of endosymbiont Wolbachia in the common bed bug, Cimex lectularius. Sci Rep. 2018;8:9.

48. Mamidala P, Rajarapu SP, Jones SC, Mittapalli O. Identification and validation of reference genes for quantitative real-time polymerase chain reaction in Cimex lectularius. J Med Entomol. 2011:48:947-51.

49. Henzel A, Brum MCS, Lautert C, Martins M, Lovato LT, Weiblen R. Isolation and identification of feline calicivirus and feline herpesvirus in southern Brazil. Braz J Microbiol. 2012;43:560-8.

50. Bae J, Schwab KJ. Evaluation of murine norovirus, feline calicivirus, poliovirus, and MS2 as surrogates for human norovirus in a model of viral persistence in surface water and groundwater. Appl Environ Microbiol. 2008;74:477-84.

51. Bidawid S, Malik N, Adegbunrin O, Sattar SA, Farber JM. A feline kidney cell line-based plaque assay for feline calicivirus, a surrogate for Norwalk virus. J Virol Methods. 2003;107:163-7.

52. Reed L, Muench H. A simple method for estimating fifty percent endpoints. Am J Epidemiol. 1938;27:493-7.

53. Usinger RL. Monograph of Cimicidae (Hemiptera, Heteroptera). College Park: Entomological Society of America; 1966.

54. Goddard J, de Shazo R. Psychological effects of bed bug attacks (Cimex lectularius L.). Am J Med. 2012;125:101-3.

55. Reinhardt K, Siva-Jothy MT. Biology of the bed bugs (Cimicidae). Annu Rev Entomol. 2007:52:351-74.

56. Jupp PG, Lyons SF. Experimental assessment of bedbugs (Cimex lectularius and Cimex hemipterus) and mosquitoes (Aedes aegypti formosus) as vectors of human immunodeficiency virus. AIDS. 1987;1:171-4.

57. Burton GJ. Bedbugs in relation to transmission of human diseases. Public Health Rep. 1963;78:513-24.

58. Benoit JB, Adelman ZN, Reinhardt K, Dolan A, Poelchau M, Jennings EC, et al. Unique features of a global human ectoparasite identified through sequencing of the bed bug genome. Nat Commun. 2016;7:10165.

59. Douglas AE. Multiorganismal insects: diversity and function of resident microorganisms. Annu Rev Entomol. 2015;60:17-34.

60. Harrison JF. Insect acid-base physiology. Annu Rev Entomol. 2001;46:221-50.

61. Douglas A. Alimentary canal, digestion and absorption. In: Simpson S, Douglas A, editors. The insects: structure and function. Cambridge: Cambridge University Press; 2013. p. 46-80.

62. Lee KM, Gillespie JH. Thermal and pH stability of feline calicivirus. Infect Immun. 1973;7:678-9.

63. Peters W. Peritrophic membranes, vol. 30. Heidelberg: Springer; 2012.

64. Ratcliffe NA, Whitten MM. Vector immunity. Microbe-vector interactions in vector-borne diseases. Cambridge: Cambridge University Press; 2004. p. 199-262.

65. Edwards MJ, Jacobs-Lorena M. Permeability and disruption of the peritrophic matrix and caecal membrane from Aedes aegypti and Anopheles gambiae mosquito larvae. J Insect Physiol. 2000;46:1313-20.

66. Shao L, Devenport M, Jacobs-Lorena M. The peritrophic matrix of hematophagous insects. Arch Insect Biochem Physiol. 2001:47:119-25.

67. Bai XD, Mamidala P, Rajarapu SP, Jones SC, Mittapalli O. Transcriptomics of the bed bug (Cimex lectularius). PLOS ONE. 2011;6:10.

68. Ye YH, Seleznev A, Flores HA, Woolfit M, McGraw EA. Gut microbiota in Drosophila melanogaster interacts with Wolbachia but does not contribute to Wolbachia-mediated antiviral protection. J Invertebr Pathol. 2017;143:18-25.

69. Wong ZS, Brownlie JC, Johnson KN. Impact of ERK activation on fly survival and Wolbachia-mediated protection during virus infection. J Gen Virol. 2016:97:1446-52.

70. Shaw AE, Veronesi E, Maurin G, Ftaich N, Guiguen F, Rixon F, et al. Drosophila melanogaster as a model organism for bluetongue virus replication and tropism. J Virol. 2012;86:9015-24.

71. Braquart-Varnier C, Lachat M, Herbiniere J, Johnson M, Caubet Y, Bouchon $\mathrm{D}$, et al. Wolbachia mediate variation of host immunocompetence. PLoS ONE. 2008:3:6.

72. Skelton E, Rances E, Frentiu FD, Kusmintarsih ES, Iturbe-Ormaetxe I, Caragata EP, et al. A native Wolbachia endosymbiont does not limit dengue 
virus infection in the mosquito Aedes notoscriptus (Diptera: Culicidae). J Med Entomol. 2016;53:401-8.

73. Johnson KN. The impact of Wolbachia on virus infection in mosquitoes. Viruses. 2015;7:5705-17.

74. Adelman ZN, Miller DM, Myles KM. Bed bugs and infectious disease: a case for the arboviruses. PLoS Pathog. 2013;9:e1003462.

75. Brown CR, Brown MB. Between-group transmission dynamics of the swallow bug, Oeciacus vicarius. J Vector Ecol. 2005;30:137-43.

76. Rush WA, Francy DB, Smith GC, Cropp CB. Transmission of an arbovirus by a member of the family Cimicidae. Ann Entomol Soc Am. 1980;73:315-8.
77. Steelman CD, Szalanski AL, Trout R, McKern JA, Solorzano C, Austin JW. Susceptibility of the bed bug Cimex lectularius L. (Heteroptera: Cimicidae) collected in poultry production facilities to selected insecticides. J Agric Urban Entomol. 2008;25:41-51.

\section{Publisher's Note}

Springer Nature remains neutral with regard to jurisdictional claims in published maps and institutional affiliations.
Ready to submit your research? Choose BMC and benefit from:

- fast, convenient online submission

- thorough peer review by experienced researchers in your field

- rapid publication on acceptance

- support for research data, including large and complex data types

- gold Open Access which fosters wider collaboration and increased citations

- maximum visibility for your research: over 100M website views per year

At BMC, research is always in progress.

Learn more biomedcentral.com/submissions 